\title{
Avaliação da estabilidade de geleias de amora-preta acondicionadas em diferentes embalagens
}

\section{Evaluation of stability of blackberry jams conditioned in different packaging materials}

Ludmilla Magalhães CARNEIRO ${ }^{[1, *]}$ (D), Caroline Roberta Freitas PIRES ${ }^{[1]}$ (D), Juliana Pinto de LIMA ${ }^{[2]}$ (D), Patrícia Aparecida Pimenta PEREIRA ${ }^{[3]}$ (D) Luiz Carlos de Oliveira LIMA ${ }^{[4]}$ (D)

[1] Universidade Federal do Tocantins (UFT), Campus Palmas. Avenida NS 15, 109 Norte - Plano Diretor Norte, 77001-090. Palmas, TO, Brasil. carolinerfpires@uft.edu.br

[2] Instituto de Ciências Agrárias (ICA), Universidade Federal de Minas Gerais (UFMG), Campus Regional de Montes Claros. Avenida Universitária, 1.000. Bairro Universitário, 39.404-547. Montes Claros, MG, Brasil. jujuufv@hotmail.com

[3] Universidade Federal de Ouro Preto (UFOP), Rua Diogo de Vasconcelos, 122. Pilar, 35400-000. Ouro Preto, MG, Brasil. pattyap2001@yahoo.com.br [4] Universidade Federal de Lavras (UFLA), Avenida Doutor Sylvio Menicucci, 1001 - Kennedy, 37200-000. Lavras, MG, Brasil. Icolima@ufla.edu.br

*Autor para correspondência: luddygyn@hotmail.com

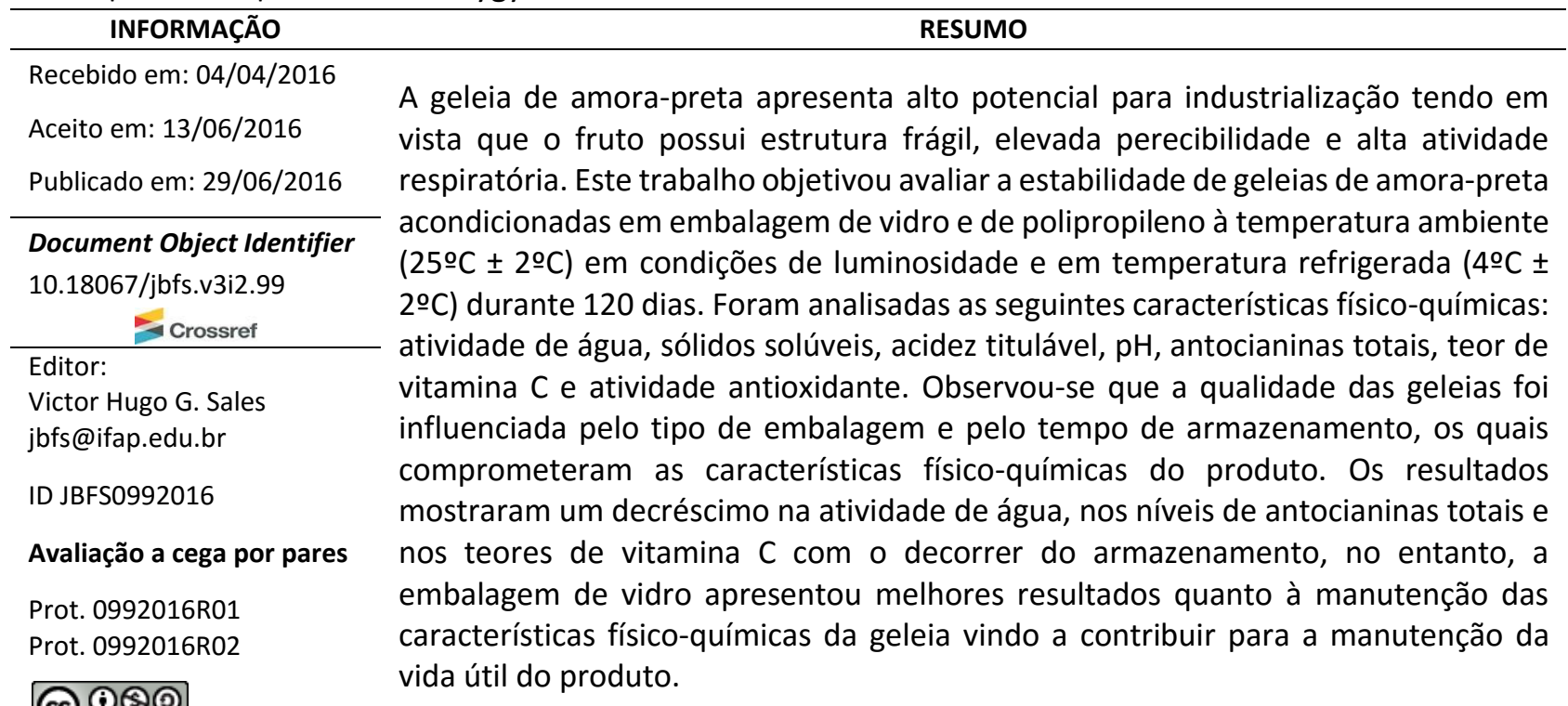

Palavras-chave: Amora-preta. Geleia. Embalagens. Qualidade.

ABSTRACT - The blackberry jam has a high potential for industrialization, in order that the fruit has a fragile structure, high perishability, and high respiratory activity. This study evaluated the stability of blackberry jams packed in glass and polypropylene at temperature $(25 \pm 2 \circ \mathrm{O})$ in light conditions and refrigerated temperature $\left(4^{\circ} \mathrm{C} \pm 2^{\circ} \mathrm{O} C\right)$ for 120 days. The physico and chemical characteristics were analyzed: water activity, soluble solids, titratable acidity, $\mathrm{pH}$, total anthocyanins and the content of vitamin $\mathrm{C}$. It was observed that the quality of jams was influenced by the type of packaging and the storage time, which committed the nutritional characteristics of the product. The results showed a decrease in water activity, the levels of anthocyanins and vitamin C with the time of storage, however, the glass packaging showed better values for the maintenance of the physico-chemical characteristics jams been contribute to maintaining the shelf-life of the product.

Keywords: Blackberry. Jam. Packaging materials. Quality

Financiamento: Os autores reportam que não houve suporte e auxílio financeiro.

Conflito de interesse: Os autores declaram que não há conflito de interesse.

Como citar esse documento (ABNT):

CARNEIRO, L.M.; PIRES, C.R.F.; LIMA, J.P.; PEREIRA, P.P.A.; LIMA, L.C.O. Avaliação da estabilidade de geleias de amora preta acondicionadas em diferentes embalagens. Journal of Bioenergy and Food Science, v.3, n.2, p.89-102, 2016. DOI:10.18067/jbfs.v3i2.99 


\section{INTRODUÇÃO}

A amora-preta (Rubus spp.) é um fruto que se caracteriza por apresentar tamanho reduzido, forma globular e suculência. Esta espécie arbustiva tem porte ereto ou rasteiro, contém frutos agregados em forma de drupas que envolvem o receptáculo, chegam a pesar de quatro a sete gramas, de cor negra arroxeada e gosto ácido a doce-ácido. Possui baixo custo de produção, fácil manejo e pouca utilização de praguicidas. ${ }^{1}$

As amoras-pretas são frutas de alta qualidade nutricional e valor econômico significativo ${ }^{2}$, elas são ricas em vitamina C e contém em torno de $85 \%$ de água, cerca de $10 \%$ de carboidratos, elevado conteúdo de minerais, vitaminas do complexo $B$ e $A$, além de ser fonte de compostos bioativos, sendo considerada uma fruta funcional, pois, além das características nutricionais básicas, quando consumida como parte usual da alimentação, produz efeito fisiológico/metabólico benéfico à saúde humana ${ }^{3}$ contendo excelentes fontes de antioxidantes naturais ${ }^{4}$, como as antocianinas ${ }^{5}$ e os polifenóis ${ }^{6,7}$

O fruto apresenta elevada produção de etileno e grande quantidade de água em seu interior o que facilita a ocorrência de alterações fisiológicas na textura e deterioração microbiológica ${ }^{8}$ restringindo sua vida útil pós-colheita. No entanto, para o aproveitamento econômico desses frutos, alternativas tais como a industrialização na forma de doces, sobremesas, caldas, polpas, sorvetes e geleias têm sido estudadas. ${ }^{1,9,10}$

Segundo a Resolução CNNPA no 12 de 1978, geleia de frutas é o produto obtido pela cocção de frutas inteiras ou em pedaços, polpa ou suco de frutas, com açúcar, água e concentrado até consistência gelatinosa. Podendo sofrer adição de glicose ou açúcar invertido para conferir brilho ao produto. Não podendo ser colorida nem aromatizada artificialmente, sendo permitida a adição de acidulantes e pectina para reposição de qualquer deficiência no conteúdo natural de pectina e/ou de acidez da fruta. A consistência deve ser semissólida, cor e cheiro devem ser característicos da fruta de origem; o sabor deve ser doce, semiácido, de acordo com a fruta de origem. ${ }^{11}$

As geleias são consideradas como o segundo produto em importância comercial para a indústria de conservas de frutas brasileira, sendo utilizadas usualmente em acompanhamentos de pão, torradas, bolachas e derivados, ou adicionadas em recheio de bolo. ${ }^{12}$

Após processadas, as geleias apresentam uma vida útil prolongada devido à baixa atividade de água do alimento que desfavorece o crescimento da maioria dos microrganismos. No entanto, a preservação das características originais dos alimentos por um maior período após o seu processamento consiste num grande desafio, visto que, as condições do ambiente de armazenamento, tais como temperatura, umidade, luminosidade, bem como o tipo do material da embalagem utilizada, são aspectos que devem ser avaliados e controlados, visando à manutenção da qualidade dos produtos durante a sua vida-de-prateleira. ${ }^{13}$

Face ao exposto acima, o presente trabalho teve como objetivo avaliar a estabilidade físicoquímica da geleia de amora-preta acondicionada em diferentes embalagens por 120 dias de armazenamento.

\section{MATERIAL E MÉTODOS}

\section{A) Matéria prima}

Frutos da cultivar Tupy foram colhidos no estágio de maturação comercial identificado pela coloração escura e uniforme da casca, na cidade de Itamonte, MG na safra de 2010/2011. Os frutos incialmente foram lavados em água corrente para a retirada de sujidades maiores e logo após foram imersos em uma solução com hipoclorito de sódio 50 ppm por 10 minutos. Em seguida foram distribuídos em embalagens de polietileno de baixa densidade e transferidos para armazenamento em freezer doméstico a $-18 \circ \mathrm{C} \pm 2 \circ \mathrm{C}$ para $\mathrm{O}$ congelamento. Os frutos foram mantidos congelados até o processamento.

\section{B) Elaboração das geleias}

Para a elaboração da polpa de amora utilizada na confecção das geleias, os frutos foram descongelados à baixa temperatura retirando-os do freezer e deixando-os na geladeira por seis horas com o objetivo de obter o descongelamento completo das amostras. Em seguida os frutos foram triturados em liquidificador industrial de 10 litros por dois minutos e a polpa obtida foi coada em tecido tipo organza para a retenção das sementes. $\mathrm{O} \mathrm{pH}$ da polpa obtida foi avaliado. Segundo $\mathrm{CETEC}^{13}$, 
o pH ótimo para a formação do gel é de 3,0 a 3,2. Como os valores de $\mathrm{pH}$ obtidos para a polpa ficaram na faixa de 3,1 não foi necessária a adição de agente acidificante na formulação da geleia. A proporção de polpa: açúcar utilizado foi de 0,5: 0,5 (p/p) e 1,0\% de pectina cítrica. A cocção foi feita em tacho aberto com agitação manual contínua. $O$ ponto final foi determinado quando se atingiu um valor de sólidos solúveis correspondendo a 67ºBrix, medido em refratômetro. Após a obtenção do ponto final da geleia, esta foi imediatamente transferida para potes de vidro e potes de polipropileno, ambos com capacidade de $250 \mathrm{~mL}$. Os potes de vidro e as embalagens de polipropileno foram previamente esterilizados a $121^{\circ} \mathrm{C} / 15 \mathrm{~min}$, sendo as embalagens de vidro fechadas com tampa de metal e as embalagens de polipropileno fechadas com tampas do mesmo polímero. Sequencialmente as embalagens foram invertidas e posteriormente, resfriadas em água até aproximadamente $40^{\circ} \mathrm{C}$. As geleias foram armazenadas à temperatura ambiente $\left(25 \circ \mathrm{C} \pm 2^{\circ} \mathrm{C}\right)$ e em condições de luminosidade durante 120 dias.

\section{C) Análises físico-químicas}

As análises físico-químicas da geleia foram realizadas um dia após o processamento e a cada trinta dias totalizando os 120 dias de armazenamento. A atividade de água $(A w)$ foi medida em aparelho AQUALAB (mod. CX-2, Decagon Devise, Pullman, WA). O potencial hidrogeniônico das amostras foi determinado utilizando pHmetro portátil marca INGOLD (mod. pH206), calibração feita com soluções tampão de pH 4,0 e 7,0 , a temperatura de $20^{\circ} \mathrm{C}$. A acidez titulável das amostras foi determinada por titulação com solução de $\mathrm{NaOH} 0,1 \mathrm{~N}$, usando-se fenolftaleína como indicador e os resultados expressos em porcentagem de ácido cítrico de acordo com a metodologia do Instituto Adolfo Lutz (IAL). ${ }^{15}$ Os sólidos solúveis foram determinados por refratometria, conforme as normas da Association of Official Analytical Chemists $(A O A C)^{16}$, utilizando-se refratômetro digital marca ATAGO com correção da temperatura para $20 \circ \mathrm{C}$, homogeneizando-se as amostras e transferindo de uma a duas gotas do material para o prisma do refratômetro. Os resultados foram expressos em B.Bix. O conteúdo de ácido ascórbico (vitamina $\mathrm{C}$ ) foi determinado pelo método colorimétrico, utilizando-se 2,4 dinitrofenilhidrazina, segundo Strohecker e Henning. ${ }^{17}$ A leitura foi realizada em espectrofotômetro Beckman 640 B, com sistema computadorizado, e os resultados foram expressos em $\mathrm{mg}$ de ácido ascórbico (vitamina C) por $100 \mathrm{~g}$ de geleia. O teor de antocianinas totais foi determinado pelo método da diferença de $\mathrm{pH}^{18}$, em que se dissolve a amostra em dois sistemas-tampão: cloreto de potássio $\mathrm{pH} 1,0$ $(0,025 \mathrm{M})$ e acetato de sódio $\mathrm{pH} 4,5(0,4 \mathrm{M})$. Foram adicionados $2,5 \mathrm{~mL}$ da correspondente dissolução tampão $\mathrm{pH}=1,0$ a $1,5 \mathrm{~mL}$ da amostra de geleia e 2,5 $\mathrm{mL}$ da dissolução tampão $\mathrm{pH}=4,5$ a $1,5 \mathrm{~mL}$ da amostra de geleia e as leituras das absorbâncias foram realizadas a 510 e $700 \mathrm{~nm}$. A absorbância foi calculada a partir da Equação 1.

$A=\left(A_{510 n}-A_{700 n m}\right) p H_{1,0}-\left(A_{510 n}-A_{700 n m}\right) p H_{4,5}$

Eq. (1)

A concentração de pigmentos no extrato foi calculada e representada em cianidina-3-glicosídeo, pela Equação 2.

Antocianinas $\left(m g \cdot L^{-1}\right)=\left(\frac{A \times P M \times F D}{\epsilon \times 1}\right) \times 1000$

Eq. (2)

Em que:

A = absorbância;

$\mathrm{PM}=$ massa molecular $(449,2)$;

$\mathrm{FD}$ = fator de diluição; $\mathrm{e}$

$\varepsilon=$ absortividade molar, $\mathrm{PM}=449,2$ e $\varepsilon=26900$.

Para a obtenção do extrato utilizado na determinação da atividade antioxidante (DPPH), foram pesados $2 \mathrm{~g}$ das amostras, às quais foram adicionadas $20 \mathrm{~mL}$ de metanol $50 \%$. Essa mistura foi homogeneizada e deixada em repouso por 1 hora, à temperatura ambiente. Após este período, a mistura foi centrifugada, a $14.000 \mathrm{rpm}$, por 15 minutos. O sobrenadante foi coletado e foram adicionados $20 \mathrm{~mL}$ de acetona $70 \%$ ao resíduo, que foi homogeneizado e deixado em repouso por 1 hora, à temperatura ambiente. Em seguida, centrifugou-se a $14.000 \mathrm{rpm}$, por 15 minutos. O sobrenadante foi coletado, adicionado ao primeiro sobrenadante e o volume foi completado para 50 $\mathrm{mL}$ com água destilada. A metodologia empregada na determinação da atividade antioxidante foi baseada na extinção da absorção do radical 2,2difenil-1-picril hidrazil (DPPH $60 \mu \mathrm{M}$ ), proposta por 
Rufino et al. ${ }^{19}$, com algumas adaptações em relação ao cálculo, calculando-se o percentual de sequestro do radical DPPH a partir do padrão. Adicionou-se 0,1 $\mathrm{mL}$ de cada extrato das amostras a $3,9 \mathrm{~mL}$ de solução de DPPH. Para o controle, foram adicionados $0,1 \mathrm{~mL}$ de metanol (50\%) e acetona (70\%), juntamente ao DPPH, no lugar do extrato. As leituras foram realizadas após 120 minutos, em espectrofotômetro, a $515 \mathrm{~nm}$ e os resultados foram expressos em percentual de sequestro de radical livre (\%SRL), conforme Equação 3.

$\% S R L=\frac{(A c-A m)}{A c} \times 100$

Em que:

Ac = absorbância do controle;

Am = absorbância da amostra.

\section{D) Análise estatística}

O delineamento adotado foi inteiramente casualizado com esquema fatorial $2 \times 5$ onde 0 primeiro fator corresponde aos dois tipos de embalagens (vidro e polipropileno) e o segundo fator aos cinco tempos de armazenamento (0, 30, 60, 90 e 120 dias). Foram realizadas três repetições para cada tratamento com duplicata. Os resultados das avaliações físico-químicas da geleia de amorapreta foram analisados estatisticamente pelo Programa Sisvar, utilizando-se análise de variância ANOVA e teste $F$, seguido do teste de Tukey $(p \leq 0,05)$ para comparação dos resultados médios das amostras e análise de regressão quando a variável quantitativa foi significativa. ${ }^{20}$

Para a análise de correlação foi utilizado o Programa R.

\section{RESULTADOS E DISCUSSÃO}

O processamento da amora na forma de geleia é considerado uma alternativa válida reduzindo as perdas no auge da safra e aproveitando seu aspecto funcional. As geleias obtidas apresentaram consistência firme com coloração roxa brilhante com sabor e aroma característico da amora preta.

A atividade de água das geleias foi influenciada significativamente pelo tipo de embalagem e pelo tempo de armazenamento (Tabela 1 e Figura 1), respectivamente. Geleias acondicionadas nas embalagens de polipropileno apresentaram valores de atividade de água significativamente inferiores (Tabela 1).

A figura 1 mostra uma redução na atividade de água ao longo do tempo de armazenamento em ambas as embalagens. Esta redução se deve provavelmente a hidrólise de açúcares não redutores a redutores, os quais são mais higroscópicos e depressores de atividade de água. ${ }^{21}$

A embalagem de vidro apresentou maior conservação da atividade da água na geleia durante o tempo de armazenamento, provavelmente,

Tabela 1. Valores médios das características físico-químicas de geleias de amora acondicionadas em diferentes embalagens.

Table 1. Averages values of the physicochemical characteristics of blackberry jelly wrapped in different packaging.

\begin{tabular}{lcc}
\hline \multirow{2}{*}{ Características físico-químicas } & \multicolumn{2}{c}{ Embalagens } \\
\cline { 2 - 3 } & $0,800 \mathrm{a}$ & Polipropileno \\
\hline Atividade de Água & $67,39 \mathrm{~b}$ & $0,797 \mathrm{~b}$ \\
Sólidos Solúveis ( ${ }^{\circ}$ Brix) & $0,86 \mathrm{a}$ & $68,79 \mathrm{a}$ \\
Acidez Titulável (\% de ácido cítrico) & $3,16 \mathrm{a}$ & $0,87 \mathrm{a}$ \\
$\mathrm{pH}$ & $49,90 \mathrm{a}$ & $3,15 \mathrm{a}$ \\
Antocianinas Totais $\left(\mathrm{mg}^{-{ }^{-1}}\right)$ & $45,24 \mathrm{a}$ & $43,09 \mathrm{~b}$ \\
Vitamina C (mg/100g $\left.{ }^{-1}\right)$ & $65,37 \mathrm{a}$ & $36,54 \mathrm{~b}$ \\
Atividade Antioxidante- DPPH (\%SRL) & $62,32 \mathrm{~b}$ \\
\hline
\end{tabular}

*Médias seguidas de letras iguais na mesma linha não se diferem significativamente a nível de $5 \%$ de probabilidade.

*Averages followed by the same letter in a line are not significantly different at the 5\% probability level. 


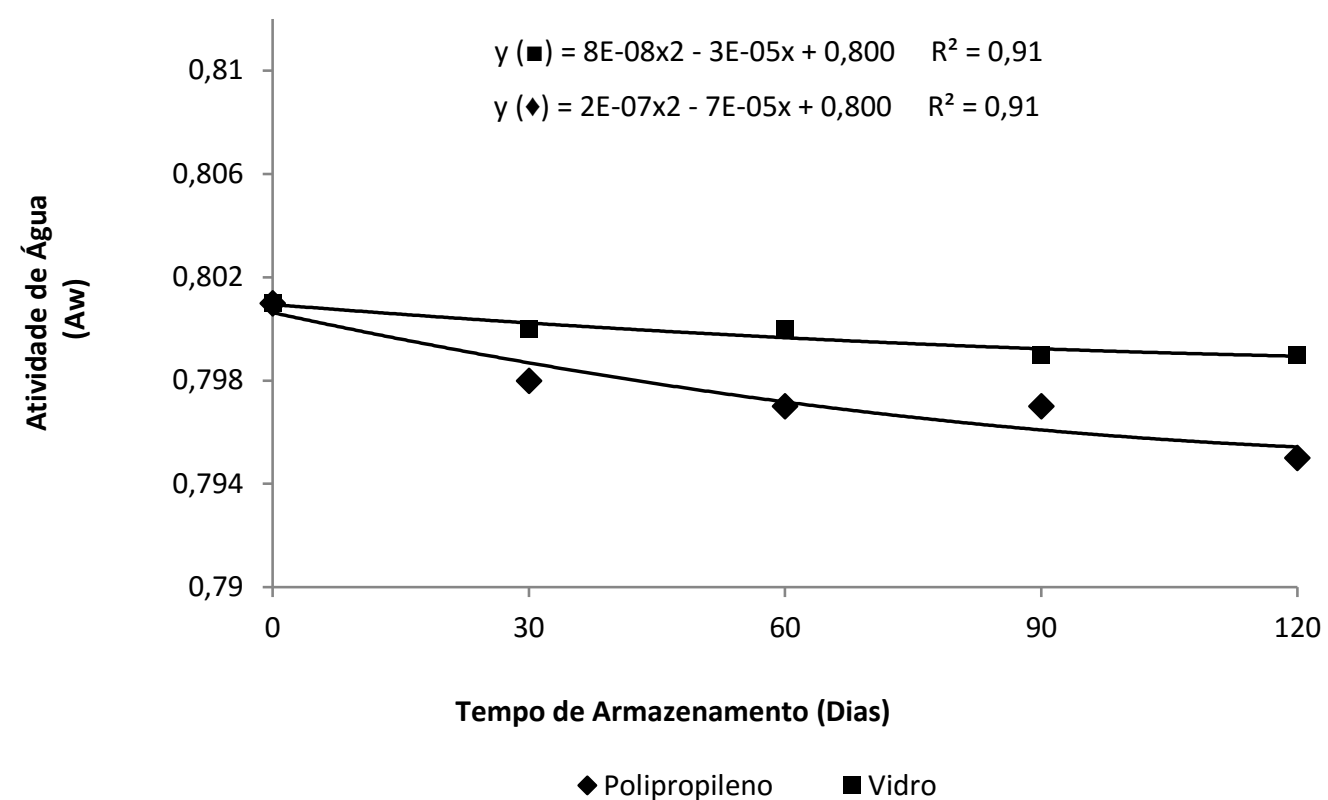

Figura 1. Efeito do armazenamento sobre a atividade de água de geleia de amora-preta acondicionada em diferentes embalagens

Figure 1. Effect of storage on the water activity of blackberry jelly wrapped in different packaging

devido a menor interação do produto com o meio ambiente e eficiente sistema de fechamento, corroborando com os dados encontrados por Assis ${ }^{22}$ que ao estudarem o processamento e estabilidade da geleia de caju, o parâmetro atividade de água manteve-se constante durante o armazenamento em embalagens de vidro.

Maior decréscimo da atividade de água foi observado na embalagem de polipropileno com o decorrer do tempo de armazenamento (Figura 1).

Tendências similares foram encontradas no estudo do armazenamento de doce em massa de casca de maracujá e de doce de umbu verde durante 90 dias por Nascimento, Borges e Oliveira ${ }^{23}$ e Policarpo et al. $^{24}$, respectivamente. Ao final do armazenamento, a geleia envasada no polipropileno apresentou maior redução na atividade de água, que pode estar associada à evaporação de água durante $o$ armazenamento provocada pela natureza porosa da embalagem de polipropileno. ${ }^{21}$

O valor de atividade de água tem grande importância na área de tecnologia de alimentos, permitindo avaliar a suscetibilidade de deterioração dos alimentos e, consequentemente, vida de prateleira do produto. De acordo com Broomes e Badrie $^{25}$, a atividade de água determina o limite inferior de água disponível para o crescimento microbiano. Em geral, a atividade de água mínima para o desenvolvimento da maioria dos bolores e leveduras é de 0,80 e 0,85 , respectivamente. Considerando esses valores, todas as geleias estão susceptíveis ao crescimento de bolores, segundo as condições de processamento e a influência de outros fatores intrínsecos.

De acordo com os dados da Tabela 1 houve diferença significativa no teor de sólidos solúveis totais das geleias acondicionadas em diferentes embalagens. As geleias armazenadas em embalagens de polipropileno apresentaram valores significativamente superior.

Os sólidos solúveis também foram influenciados significativamente pelo tempo de armazenamento. As geleias acondicionadas nas embalagens de vidro sofreram pequena variação com o tempo de armazenamento, no entanto, as geleias que foram armazenadas nas embalagens de polipropileno apresentaram um maior incremento nos teores de sólidos solúveis com o decorrer dos dias (Figura 2). 


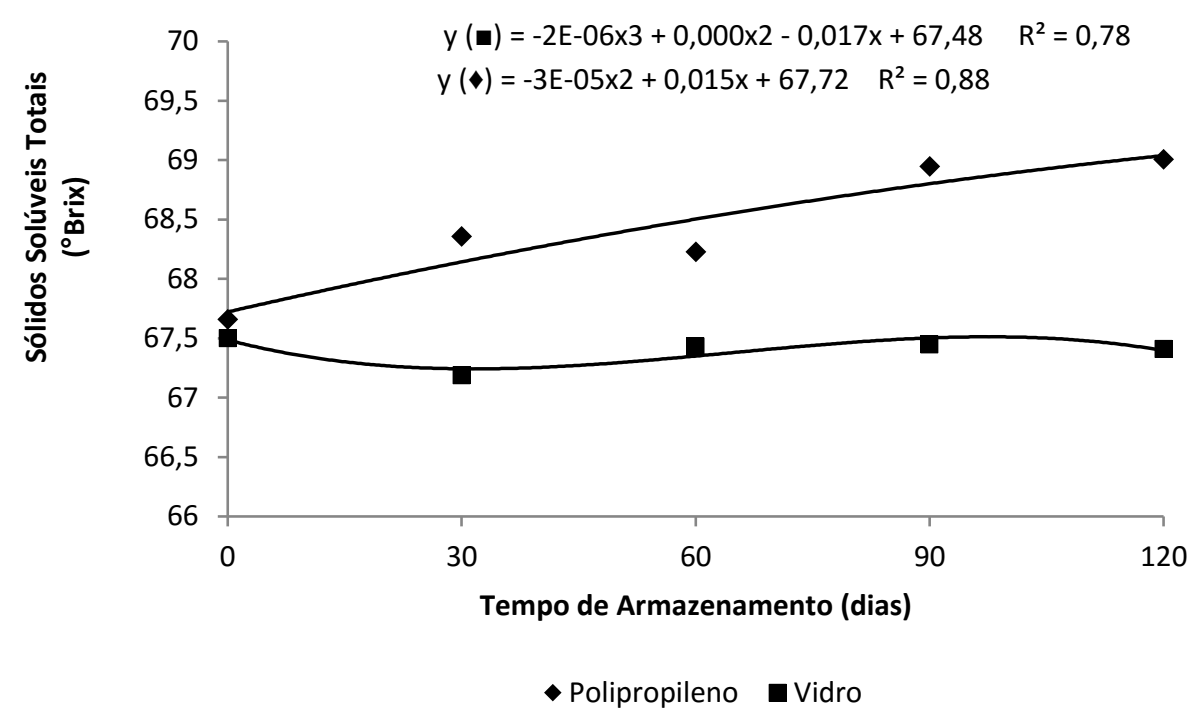

Figura 2. Efeito do armazenamento sobre o teor de sólidos solúveis de geleia de amora-preta acondicionada em diferentes embalagens

Figure 2. Effect of storage on soluble solids content of blackberry jelly wrapped in different packaging

O aumento dos sólidos solúveis ocorreu, provavelmente, devido à evaporação de água durante a estocagem a temperatura ambiente $(25 \circ \mathrm{C})$. Sendo possível que a permeabilidade do material de embalagem ${ }^{26}$ tenha permitido a migração da água para o ambiente.

Comportamento semelhante foi observado por Rocha e Magalhães ${ }^{27}$ no acompanhamento de vida de prateleira de doce de manga espada, cujoteor de sólidos solúveis aumentou com o decorrer dos 180 dias de armazenamento.

Policarpo et al. ${ }^{24}$ analisando a conservação de doce de umbu verde armazenado em embalagens de polipropileno na temperatura de $33^{\circ} \mathrm{C}$ durante 90 dias, observou aumento de sólidos solúveis em todas as formulações estudadas, assim como Nascimento, Borges e Oliveira ${ }^{23}$, em trabalho similar com doce em massa de casca de maracujá.

Apesar de o tempo de armazenamento ter causado modificações no teor de sólidos solúveis da geleia de amora-preta, os valores se encontraram acima do mínimo estabelecido pelo Regulamento Técnico para Fabricação de Geleia de Frutas que é de $65 \%{ }^{11}$ Ao avaliar o teor de sólidos solúveis na geleia de caju, Assis ${ }^{22}$ observaram que não houve variação significativa dos valores após o primeiro mês de armazenamento, no entanto, Mota ${ }^{1}$ registrou decréscimo nos teores de sólidos solúveis no decorrer do armazenamento em todas as formulações de geleia de amora-preta estudadas.

A variável acidez titulável na geleia não foi influenciada significativamente pelo tempo de armazenamento nem pelo tipo de embalagem utilizada. Geleias acondicionadas na embalagem de vidro e de polipropileno apresentaram valores médios de 0,86 e 0,87 \% de ácido cítrico, respectivamente.

Mota ${ }^{1}$ ao avaliar a acidez titulável de geleia de amora preta observou uma redução nos teores com o decorrer dos 90 dias de armazenamento. Resultado oposto foi encontrado no trabalho de Zambiazi, Chim e Bruscatto ${ }^{28}$, avaliando geleias light e geleias convencionais de morango por 120 dias que durante o período de estocagem observaram uma pequena elevação no teor de acidez, principalmente nas formulações light. Os autores atribuíram este acréscimo a reações de interação e degradação que ocorrem liberando íons $\mathrm{H}^{+}$no meio e ao metabolismo de bactérias.

Não houve diferença significativa nos valores de $\mathrm{pH}$ das geleias acondicionadas em diferentes embalagens (Tabela 1). No entanto, observa-se na Figura 3 que o tempo de armazenamento 


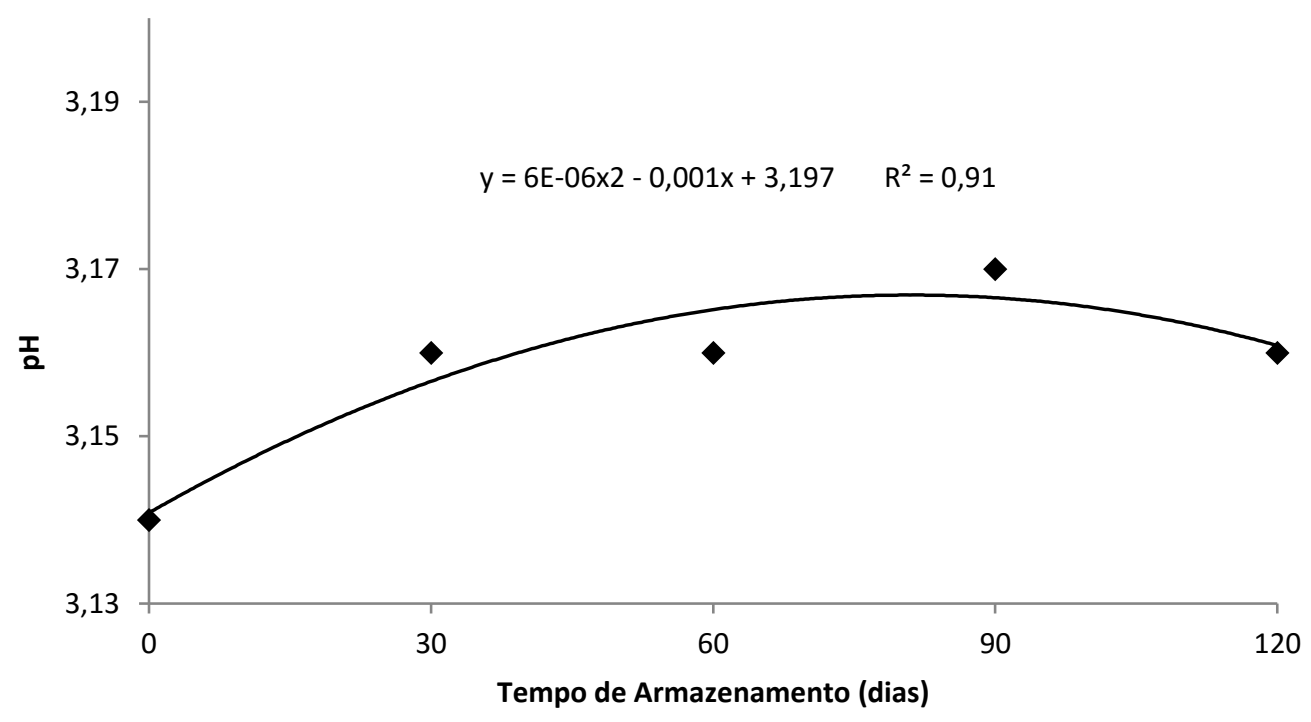

Figura 3. Efeito do armazenamento sobre $\mathrm{o} p \mathrm{pH}$ de geleia de amora-preta acondicionada em diferentes embalagens

Figure 3. Effect of storage on the $\mathrm{pH}$ of blackberry jelly wrapped in different packaging

influenciou significativamente os valores desta variável.

Observa-se pela figura 3 , uma tendência à elevação do $\mathrm{pH}$ das geleias até os 90 dias com pequena redução dos valores ao término do armazenamento. Comportamento semelhante foi constatado por Silva ${ }^{29}$, em polpa de acerola armazenada congelada, o qual inferiu que este aumento do $\mathrm{pH}$ está intimamente relacionado com a degradação do ácido ascórbico durante o armazenamento.

Entretanto, Nachtigall et al. ${ }^{30}$ observaram um decréscimo de $\mathrm{pH}$ durante o armazenamento de geleia de amora-preta de baixa caloria elaborada com $0,5 \%$ de pectina cujo $\mathrm{pH}$ inicial foi de 3,10 e após 90 dias reduziu para 3,00. Isso se deve provavelmente à liberação de íons $\mathrm{H}^{+}$no meio em razão do ácido adicionado.

O conteúdo de antocianinas foi influenciado significativamente pelo tipo de embalagem (Tabela 1) e pelo tempo de armazenamento (Figura 4). As geleias armazenadas nas embalagens de vidro apresentaram valores significativamente superior de antocianinas que as geleias acondicionadas em recipientes de polipropileno (Tabela 1 ).
Segundo Freitas et al. ${ }^{31}$ a redução dos teores de antocianinas está relacionada com a permeabilidade da embalagem utilizada, visto que, a presença de oxigênio no meio é um fator significativo na degradação de antocianinas, que pode ocorrer através de um mecanismo de oxidação direta ou indireta dos constituintes do meio que reagem com as antocianinas mesmo na ausência de luz, em todos os valores de pH. Daravingas e Cain ${ }^{32}$ estudaram a degradação de antocianinas do suco de framboesa e constataram que o segundo fator em ordem de importância, após o pH, na degradação do pigmento foi a presença do oxigênio molecular.

O conteúdo de ácido ascórbico e seus produtos de degradação, segundo Kirca, Ozkan e Cemeroglu ${ }^{33}$, também aceleram a degradação das antocianinas.

Ao avaliar o teor de antocianinas na geleia de amora preta, Mota ${ }^{1}$ relatou que o processamento reduziu o teor inicial de antocianinas. A geleia apresentou teores de antocianinas totais em média $8,8 \%$ inferiores aos encontrados na polpa. Além disso, a autora afirmou que o armazenamento à temperatura ambiente das geleias em recipientes de vidro transparente resultou em perdas de $32 \%$ do 


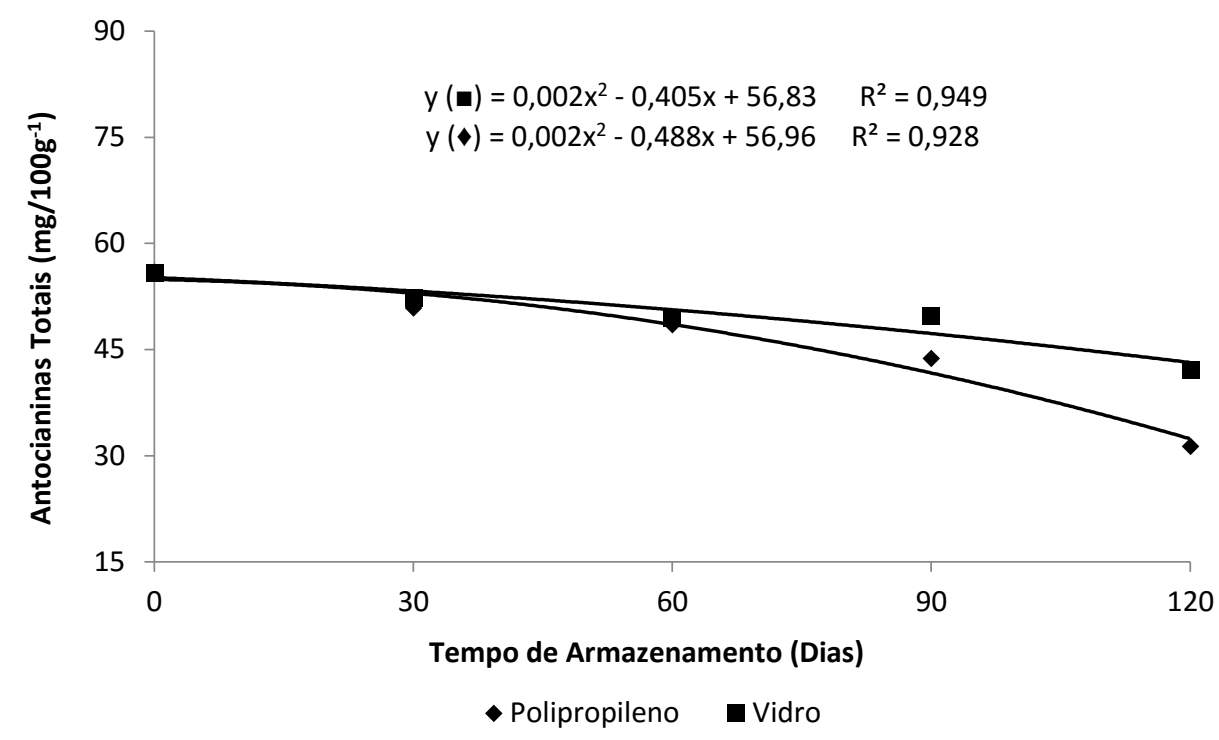

Figura 4 - Efeito do armazenamento sobre o teor de antocianinas de geleia de amora-preta acondicionada em diferentes embalagens

Figure 4- Effect of storage on anthocyanins content of blackberry jelly wrapped in different packaging

conteúdo de antocianinas nos primeiros 40 dias de estocagem e outros $11 \%$ nos 50 dias subsequentes. ${ }^{9}$

Estudos realizados em suco de amora-preta reforçam a ideia de que as antocianinas sofrem redução pós-processamento. Mota ${ }^{1}$ demonstrou que ocorreu uma redução de $42 \%$ do teor inicial de antocianinas através da elaboração de um suco por extração através de vapor.

No presente estudo observou-se que para as geleias acondicionadas em embalagens de polipropileno houve uma perda de aproximadamente $43 \%$ no teor de antocianinas, enquanto que para as geleias acondicionadas nas embalagens de vidro esta perda foi de $24 \%$ após os 120 dias de armazenamento da geleia de amora-preta.

O teor de vitamina $\mathrm{C}$ foi influenciado significativamente pelo tipo de embalagem e pelo tempo de armazenamento (Tabela 1 e Figura 5) respectivamente.

As geleias de amora-preta acondicionadas em embalagens de polipropileno apresentaram maior redução no teor de vitamina $\mathrm{C}$ com o tempo de armazenamento quando comparado com as geleias armazenadas em embalagens de vidro (Tabela 1). Ambas as embalagens evidenciaram acentuada redução do teor de ácido ascórbico a partir dos 90 dias de armazenamento (Figura 5).

A vitamina $C$ é muito instável, podendo desta forma, ocorrer alta degradação durante a fabricação da geleia, uma vez que são necessárias etapas como fragmentação, homogeneização e concentração em elevada temperatura até níveis altos de sólidos solúveis ou completo tratamento térmico de pasteurização. ${ }^{34}$ Além disso, a vitamina $\mathrm{C}$ se degrada rapidamente em solução aquosa tanto em condições anaeróbicas como aeróbicas, especialmente quando exposta ao calor, luz, $\mathrm{pH}$, açúcares, aminoácidos livres, sendo acelerada pela presença de frutose, sacarose e de íons metálicos $\left(\mathrm{Cu}^{++}\right.$e $\left.\mathrm{Fe}^{+++}\right)$, dando diferentes produtos de degradação, tais como furfural, hidroximetilfurfural, ácido dehidroascórbico, ácido dicetogulônico, $\mathrm{CO}_{2} \mathrm{e}$ $\mathrm{H}_{2} \mathrm{O}_{2} \cdot{ }^{29,35}$

Os resultados do presente trabalho demonstraram que a permeabilidade ao oxigênio da embalagem de polipropileno poderá ser uma possível causa da menor retenção (58\%) dos teores de ácido ascórbico comparativamente às geleias acondicionadas nas embalagens de vidro (70,73\%).

Em estudo sobre a influência da embalagem e 


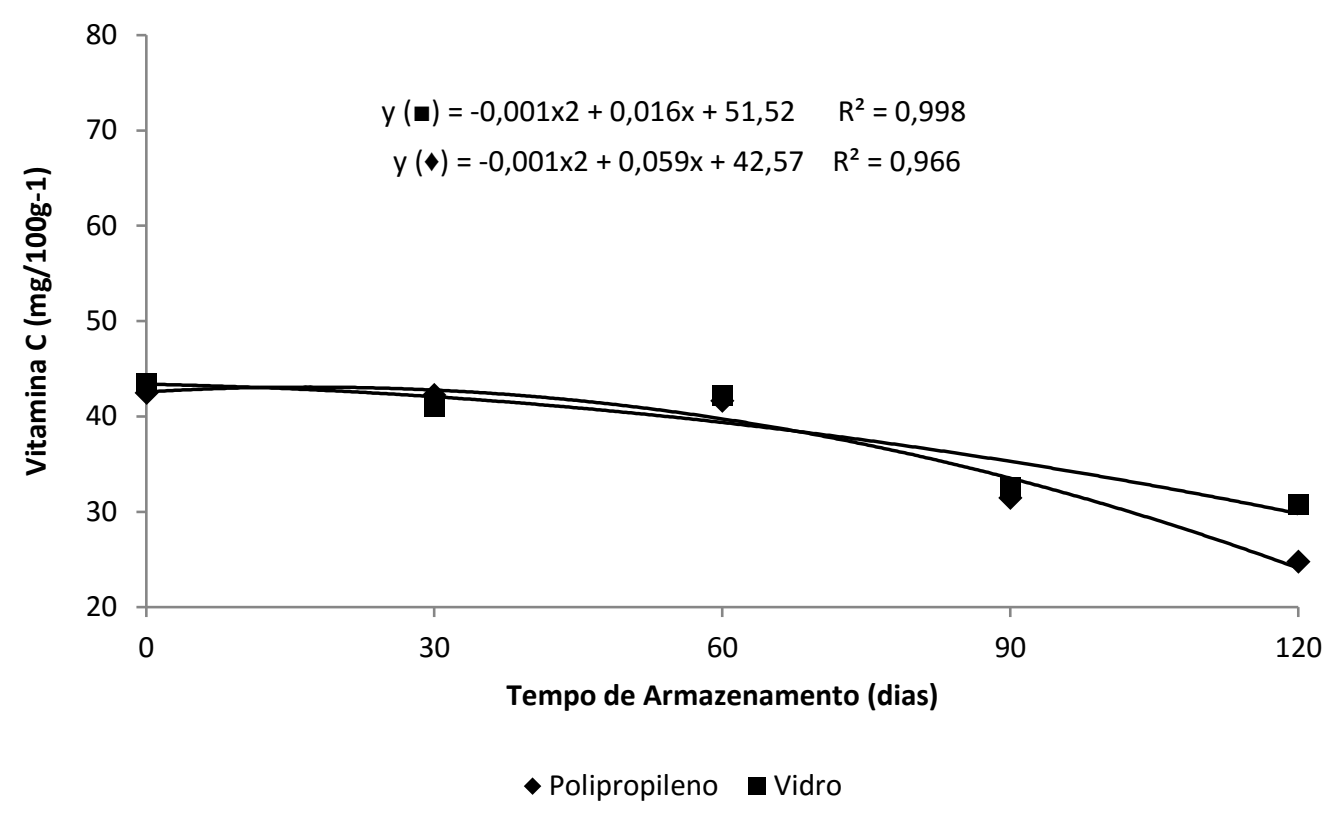

Figura 5. Efeito do armazenamento sobre os teores de vitamina $\mathrm{C}$ de geleia de amora-preta acondicionada em diferentes embalagens

Figure 5. Effect of storage on vitamin C content of blackberry jelly wrapped in different packaging

temperatura de estocagem do suco de laranja integral e concentrado na retenção do ácido ascórbico, em embalagens de vidro, polietileno rígido, poliestireno de alto impacto e cartonadas, foi observado que o material de embalagem polietileno apresentou maior permeabilidade ao oxigênio com menor retenção da vitamina $C(30 \%)$ do que a embalagem de vidro (88\%), no armazenamento a 10 ㄷ por 100 dias. $^{36}$

Freitas et al. ${ }^{31}$ avaliaram a estabilidade da vitamina $C$ do suco de acerola adoçado, envasado em garrafas de vidro e em embalagens cartonadas durante 350 dias de armazenamento em condições similares às de comercialização $\left(28^{\circ} \mathrm{C} \pm 22^{\circ} \mathrm{C}\right)$. Os autores observaram que após o fim do experimento, houve redução nos teores de vitamina $\mathrm{C}$ da ordem de $23,61 \%$ para amostras acondicionadas em embalagens de vidro e $35,95 \%$ para as amostras acondicionadas em embalagens cartonadas, afirmando a eficiência da embalagem de vidro na retenção de vitamina $C$.

Segundo Alves e Garcia ${ }^{37}$, a incidência de luz é uma das causas da oxidação de vitamina $C$, por acelerar a reação do ácido ascórbico com grupos amino, produzindo pigmentos escuros por polimerização e provocando, ainda, degradação da cor e perdas de algumas características sensoriais nas geleias de frutas, fato este que pode estar relacionado com a redução do teor de ácido ascórbico do presente estudo, visto que as geleias não foram armazenadas na ausência da luminosidade. A influência da luz na degradação do ácido ascórbico, também foi reportada por Jawaheer, Goburdhun e Ruggoo ${ }^{38}$ os quais observaram que na estocagem por quatro meses de amostras de geleia e de suco de goiaba, a exposição à luz contribuiu para o aumento da degradação do ácido ascórbico.

A atividade antioxidante avaliada pelo método de captura do radical livre DPPH foi influenciada significativamente pelo tipo de embalagem e pelo tempo de armazenamento (Tabela 1 e Figura 6). Geleias acondicionadas em embalagens de polipropileno apresentaram valores significativamente inferiores de atividade antioxidante (Tabela 1).

Observa-se pela figura 6 que as embalagens de vidro e de polipropileno apresentaram um comportamento semelhante quanto à atividade antioxidante no decorrer dos dias de armazenamento. A partir dos 60 dias ocorreu uma redução significativa no percentual de sequestro de 


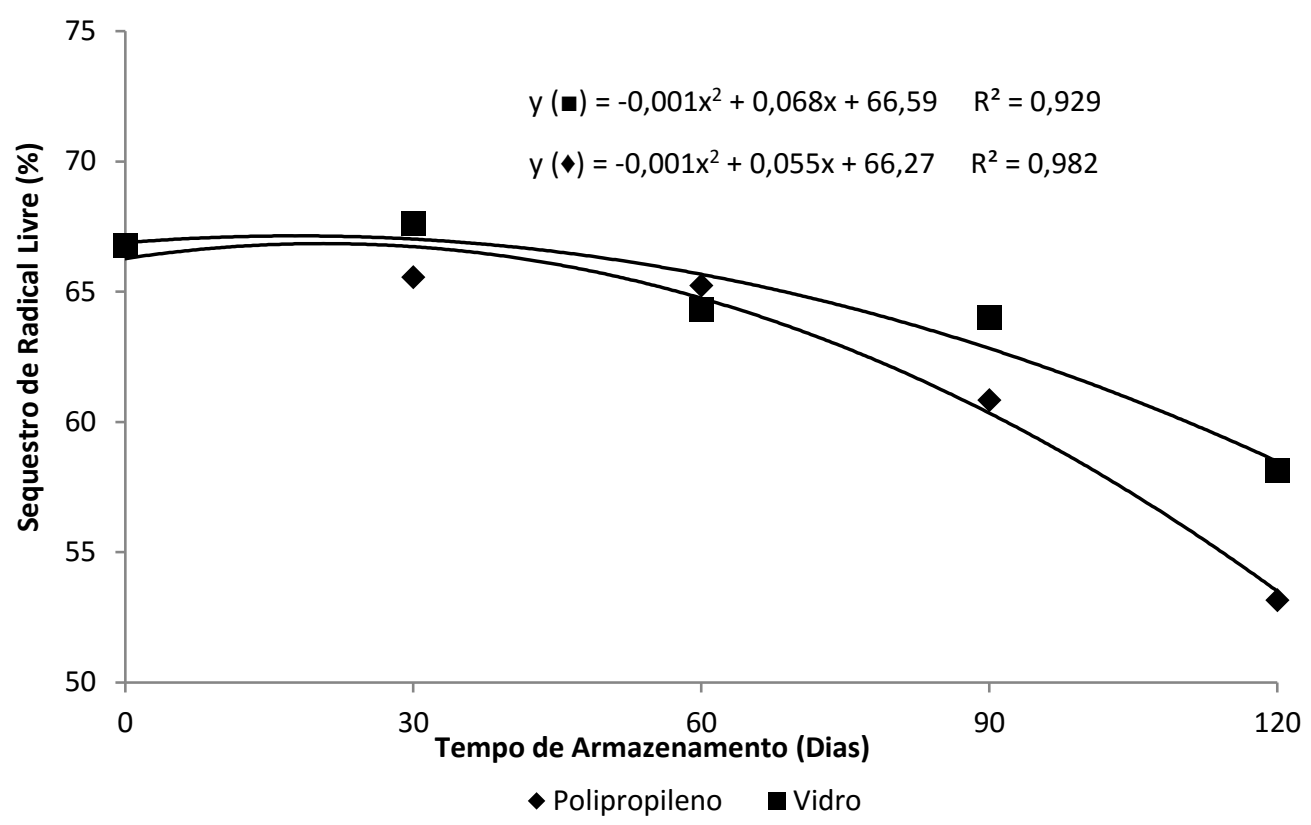

Figura 6. Efeito do armazenamento sobre o sequestro de radical livre de geleia de amora-preta acondicionada em diferentes embalagens

Figure 6. Effect of storage on free radical scavenging blackberry jelly wrapped in different packaging

radicais livres das geleias, sendo que, as geleias acondicionadas nas embalagens de vidro mantiveram maior atividade de sequestro do DPPH. Dados semelhantes foram obtidos por Daniel ${ }^{39}$ ao verificar a atividade antioxidante de licores de amora-preta pelo método de sequestro do radical DPPH. Este autor relatou que nos três primeiros meses de maturação a capacidade antioxidante das amostras de licores também diminuiu, passando de 94,19 para 50,00 mmol Trolox. $\mathrm{mL}^{-1}$.

As correlações entre os teores de ácido ascórbico e sequestro de radical livre e antocianinas totais e sequestro de radical livre estão apresentadas nas figuras 7 e 8 , respectivamente.

De acordo com a figura 7, observa-se que houve correlação positiva entre o teor de ácido ascórbico e o sequestro de radical livre.

O autor Leitão ${ }^{40}$, ao avaliar a estabilidade físico-química, microbiológica e sensorial de néctar de amora-preta (cv. Tupy) acondicionado em embalagens de polipropileno e de vidro em diferentes temperaturas (ambiente e refrigeração) durante 90 dias de armazenamento, observou através da análise de correlação, que o aumento da atividade antioxidante estava relacionado com o conteúdo de vitamina $\mathrm{C}$, corroborando com os resultados encontrados no presente estudo.

No entanto, Couto e Canniatti-Brazaca ${ }^{41}$ não encontraram correlação entre o teor de vitamina $C$ e a atividade antioxidante de sucos das diferentes variedades de laranjas e tangerinas. Além disso, Yu et al. ${ }^{42}$ relatam que outros compostos além da vitamina C contribuem com a atividade antioxidante.

De acordo com a figura 8 , observa-se que houve correlação positiva entre os valores de atividade antioxidante e de antocianinas totais na geleia de amora-preta.

Segundo Kuskoski et al. ${ }^{43}$ os maiores responsáveis pela atividade antioxidante em frutos são as antocianinas. Estes autores demonstraram que a contribuição da vitamina $C$ na atividade antioxidante de onze frutos é baixa e afirmaram que tal atividade se deve aos compostos fitoquímicos, principalmente, aos pigmentos antociânicos. Corroborando com estes resultados Katalinic et al. ${ }^{44}$ obtiveram correlação positiva entre o conteúdo de antocianinas e porcentagem de inibição de radicais em vinhos tintos, aplicando o método DPPH. 


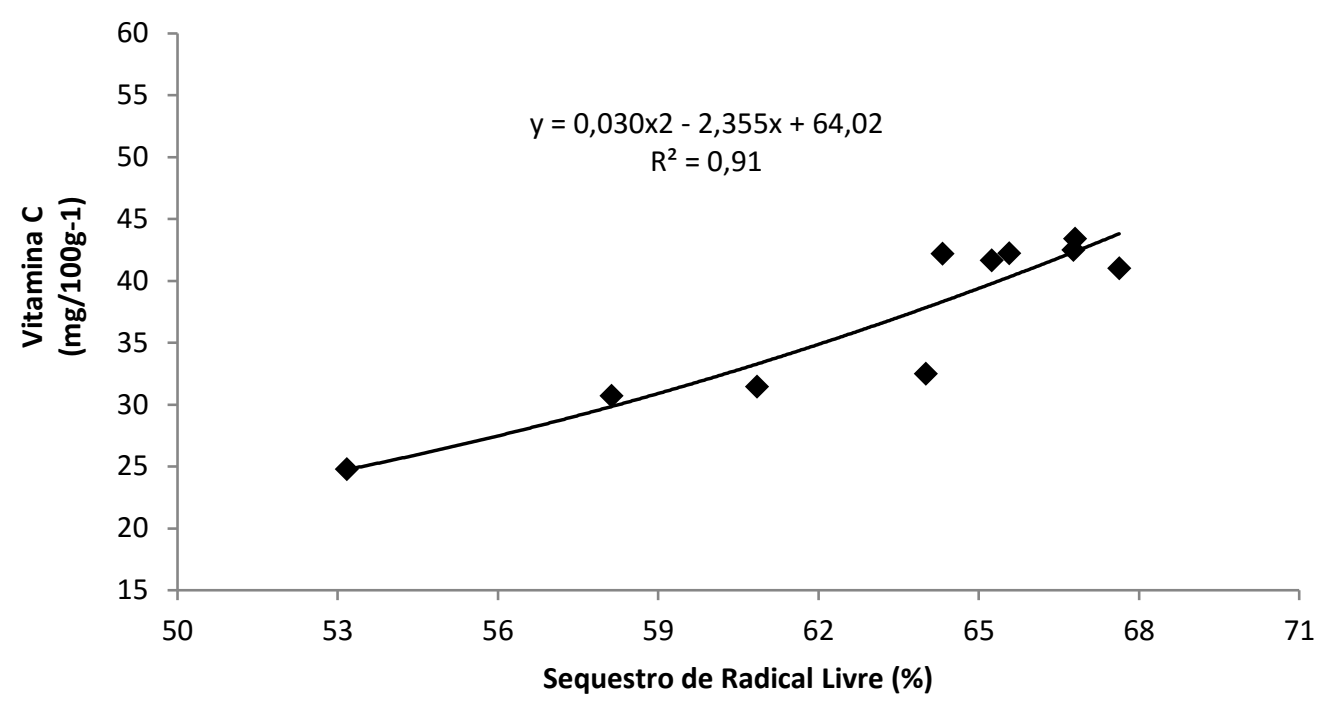

Figura 7. Correlação entre o teor de vitamina $C\left(r^{2}=0,91\right)$ e sequestro de radical livre

Figure 7. Correlation between vitamin $C$ content $\left(r^{2}=0.91\right)$ and free radical scavenging

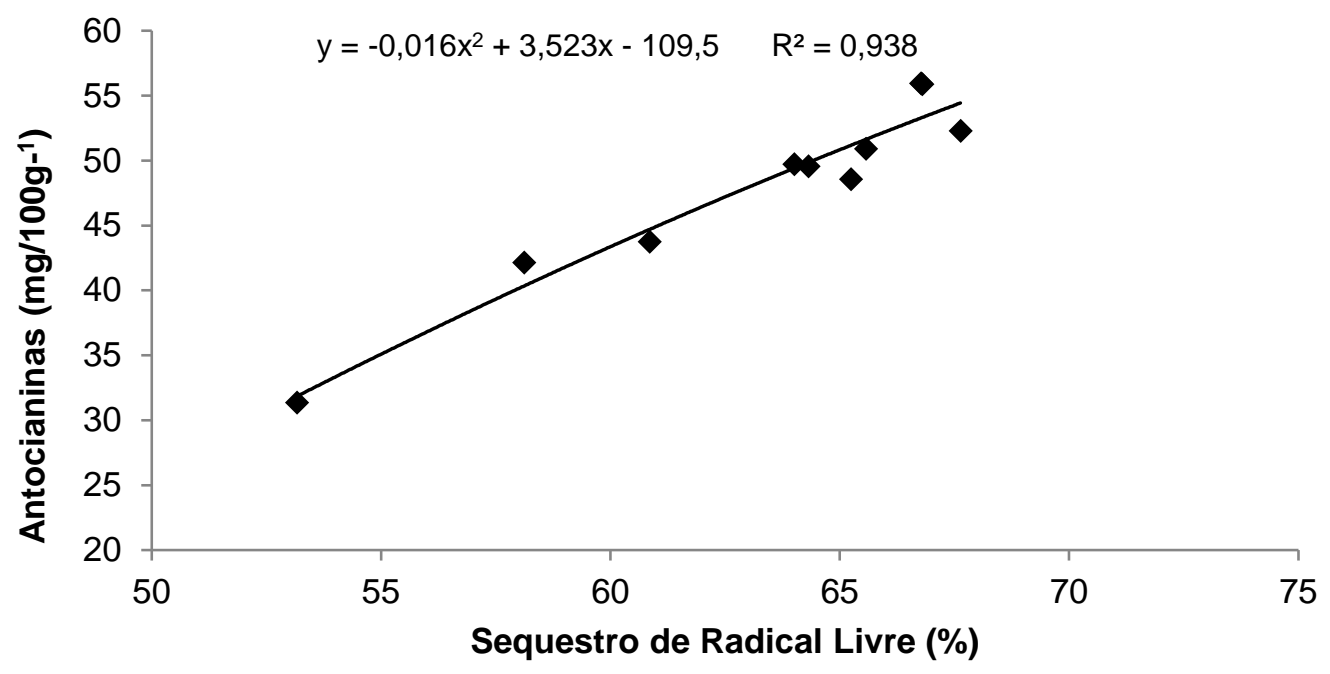

Figura 8. Correlação entre teor de antocianinas $\left(r^{2}=0,93\right)$ e os valores de porcentagem de sequestro de radical livre

Figure 8. Correlation between anthocyanins content $\left(r^{2}=0.93\right)$ and free radical scavenging

No entanto, Garcia-Alonso et al. ${ }^{45}$ verificaram em seu estudo com frutas que não existe uma correlação significativa entre a atividade antioxidante total e o conteúdo de compostos fenólicos e, afirmaram que o resultado da ação de diferentes compostos antioxidantes presentes em frutas deve-se ao possível sinergismo e efeitos antagônicos ainda desconhecidos.

\section{CONCLUSÃO}

O tempo de armazenamento mostrou influência sobre as características físico-químicas e funcionais da geleia acondicionadas em diferentes embalagens.

A embalagem de vidro foi mais eficiente em preservar as características nutricionais das geleias 
com decorrer do tempo de armazenamento, sendo uma opção viável para o acondicionamento das geleias de amora-preta.

O teor de vitamina $\mathrm{C}$ e antocianinas totais apresentou correlação positiva com o sequestro de radicais livres das geleias de amora-preta.

O processamento para a obtenção de geleia de amora-preta reduziu o teor de antocianinas e vitamina $\mathrm{C}$ da amora-preta, porém o produto ainda apresenta elevados teores destes compostos.

\section{REFERÊNCIAS BIBLIOGRÁFICAS}

1. MOTA, R.V.; Caracterização física e química de geleia de amora-preta. Ciência e Tecnologia de Alimentos, v.26, n.3, p.539-543, 2006a. Crossref

2. ANTUNES, L.E.C. Amora-preta: Nova opção de cultivo no Brasil. Ciência Rural, v.32, n.1, p.151-158, 2002.

Crossref

3. VIZZOTO, M. Amora-preta: uma fruta antioxidante. Artigo de Divulgação na Mídia Embrapa Clima Temperado, Jornal da fruta, v.195, p.14, 2008.

4. KOCA, I.; KARADENIZ, B. Antioxidant properties of blackberry and blueberry fruits grown in the Black Sea Region of Turkey. Scientia Horticulturae, v.121, n.4, p.447-450, 2009. Crossref

5. DEIGHTON, N.; BRENNAN, R.; FINN, C.; DAVIES, H.V. Antioxidant properties of domesticated and wild Rubus species. Journal of the Science of Food and Agriculture, v.80, n.2, p.1307-1313, 2000. Crossref

6. WANG, S.Y.; LIN, H.S. Antioxidant activity in fruits and leaves of blackberry, raspberry, and strawberry varies with cultivar and developmental stage. Journal of Agricultural and Food Chemistry, v.48, n.2, p.140-146, 2000. Crossref

7. MOYER, R.A.; HUMMER, K.E.; FINN, C.E.; FREI, B.; WROLSTAD, R.E. Anthocyanins, phenolics, and antioxidant capacity in diverse small fruits: Vaccinium, Rubus, and Ribes. Journal of Agricultural and Food Chemistry, v.50, n.3, p.519-525, 2002. Crossref

8. MENEGUEL, R.F.A; BENASSI, M; YAMASHITA, F. Revestimento comestível de alginato de sódio para frutos de amora-preta (Rubus ulmifolius). Revista Semina: Ciências Agrárias, v.29, n.3, p.609-618, 2008.

\section{CONTIBUIÇÃO DOS AUTORES}

\section{Desenvolvimento e condução do experimento; Elaboração do artigo científico.}

Ludmilla Magalhães Carneiro (D) e Caroline Roberta Freitas Pires $(\mathbb{D}$

\section{Orientação, avaliação, revisão e elaboração do artigo}

Juliana Pinto de Lima (D), Patrícia Aparecida Pimenta Pereira (D) e Luiz Carlos de Oliveira Lima (D), Ludmilla Magalhães Carneiro, Caroline Roberta Freitas Pires

9. MOTA, R.V.; Caracterização do suco de amora-preta elaborado em extrator caseiro. Ciência e Tecnologia de Alimentos, v.26, n.2, p.303-308, 2006b. Crossref

10. CHAGAS, E.A.; PIO, R.; BARBOSA, W.; DALL 'ORTO, F.A.C. MENDONÇA, V. Amora-preta: a pequena fruta com elevado potencial de cultivo. 2007.

11. BRASIL. Ministério da Saúde. CNNPA (Comissão Nacional de Normas e Padrões para Alimentos). Resolução n. 12/78 de 30 de março de 1978. Aprova os padrões de identidade e qualidade dos alimentos de origem vegetal. Diário Oficial [da] República Federativa do Brasil, Brasília, DF, 24 jul. 1978, Seção I.

12. MELO, E.A.; LIMA, V.L.; NASCIMENTO, P.P. Formulação e avaliação físico-química e sensorial de geleia mista de pitanga (Eugenia unifloral) e acerola (Malpighia $s p$ ). Boletim do Centro de Pesquisa de Processamento de Alimentos, v.17, n.1, p.33-44, 1999.

13. MATTA, V.M.; CABRAL, L.M.C.; SILVA, L.F.M. Suco de acerola microfiltrado: avaliação da validade-prateleira. Ciência e Tecnologia de Alimentos, v.24, n.2, p.293297, 2004. Crossref

14. FUNDAÇÃO CENTRO TECNOLÓGICO DE MINAS GERAIS-CETEC. Manual para fabricação de geléias. Belo Horizonte: CETEC, 1985. 42p.

15. INSTITUTO ADOLFO LUTZ. Normas analíticas do Instituto Adolfo Lutz. Métodos físico-químicos para análise de alimentos. 4. ed. Brasília: Ministério da Saúde, Agência Nacional de Vigilância Sanitária, 2005. $1018 \mathrm{p}$.

16. ASSOCIATION OF OFFICIAL ANALYTICAL CHEMISTS (AOAC). Official methods of analysis. 16. Ed, A.O.A.C. 1998. 
17. STROHECKER, R.; HENINING, H. M. Análisis de vitaminas: métodos comprobrados. Madrid: Paz Montalvo, 1967, p. 42.

18. GIUSTI, M. M.; WROLSTAD, R. E. Anthocyanins: characterization and measurement with uv-visible spectroscopy. In: WROLSTAD, R.E. Current protocols in food analytical chemistry, New York: John Wiley \& Sons, 2001. Unit. F1.2.1-13.

19. RUFINO, M.S.M.; FERNANDES, F.A.N.; ALVES, R.E.; BRITO, E.S. Free radical-scavenging behaviour of some north-east Brazilian fruits in a DPPH system. Food Chemistry, v.114, n.2, p.693-695, 2009. Crossref

20. FERREIRA, D.F. Análises estatísticas por meio do SISVAR (Sistema para análise de variância) para Windows versão 4.0. In: REUNIÃO ANUAL DA REGIÃO BRASILEIRA DA SOCIEDADE INTERNACIONAL DE BIOMETRIA, 45., 2000, São Carlos. Anais... São Carlos: UFSCar, 2000, P. 255-258.

21. MARTINS, M.L.A.; BORGES S.V.; CUNHA, A.C.; OLIVEIRA, F.P.; AUGUSTA, I.M.; AMORIM, E. Alterações físico-químicas e microbiológicas durante o armazenamento de doces de umbu (Spondias tuberosa Arr. Câmara) verde e maduro. Ciência e Tecnologia de Alimentos, v.30, n.1, p.60-67, 2010. Crossref

22. ASSIS, M.M.M.; MAIA, G.A.; FIGUEIREDO, E.A.T.; FIGUEIREDO, R.W.; MONTEIRO, J.C.S. Processamento e estabilidade de geleia de caju. Revista Ciência Agronômica, v.38, n.1, p.46-51, 2007.

23. NASCIMENTO, R. M. F.; BORGES, S. V.; OLIVEIRA, L. F. Alterações microbiológicas e físico-químicas de doces em massa da casca do maracujá em condições aceleradas de armazenamento. In: SIMPÓSIO DE CIÊNCIA DOS ALIMENTOS, 2., 2003, Florianópolis. Anais... Florianópolis: SIMPOCAL, 2003. CD-ROM.

24. POLICARPO, V. M. N.; BORGES, S. V.; ENDO, E.; CASTRO, F. T.; ANJOS, V. D.; CAVALCANTI, N. B. Green umbu (SpondiasTuberosa Arr. Cam.) preserve: physical, chemical and microbiological changes during storage. Journal of Food Processing and Preservation, v.31, n.2, p.201-210, 2007.

25. BROOMES, J.; BADRIE, N. Effects of low-methoxyl pectin on physicochemical and sensory properties of reduced- calorie sorrel/roselle (Hibiscus sabdariffa L.) jams. The Open Food Science Journal, v.4, p.48-55, 2010.

26. BUREAU, G.; MULTON, J. L. Embalage de los alimentos de gran consumo. Zaragoza: Editorial Acríbia S.A., 1995. p.748.
27. ROCHA, E. M.; MAGALHÃES, M. M. A. Estudo de vida de prateleira do doce em massa de manga espada. In: CONGRESSO BRASILEIRO DE CIÊNCIA E TECNOLOGIA DE ALIMENTOS, 17., 2000, Fortaleza. Anais... Fortaleza: UFC, 2000.

28. ZAMBIAZI, R.C.; CHIM, J.F.; BRUSCATTO, M. Avaliação das características e estabilidade de geleias light de morango. Alimentos e Nutrição, v.17, n.2, p.165-170, 2006.

29. SILVA, M. de F. V. Efeito dos diferentes tratamentos e embalagens nas características da polpa de acerola e na determinação dos teores de ácido ascórbico e das antocianinas durante o armazenamento. 1999. $224 \mathrm{f}$. Tese (Doutorado em Tecnologia de Alimentos) Universidade Estadual de Campinas, Campinas, SP, 1999.

30. NACHTIGALL, A. M. et al. Geléias light de amorapreta. Boletim do Centro de Processamento de Produtos Agropecuários, v.22, n.2, p. 337-353, 2004.

31. FREITAS, C.A.S.; MAIA, G.A.; COSTA, J.M.C.; FIGUEIREDO, R. W.; RODRIGUES, M. do C.P.; SOUSA, P.H.M. de. Estabilidade do suco tropical de acerola (Malpighia emarginata d.c.) adoçado envasado pelos processos hot-fille asséptico. Ciência e Tecnologia de Alimentos, v.26, n.3, p.544-549, 2006. Crossref

32. DARAVINGAS, G.; CAIN, R.F. Thermal degradation of black raspberry anthocyanin pigments in model system. Journal of Food Science, v.33, n.2, p138-142, 1968.

33. KIRCA, A.; ÖZKAN, M.; CEMEROGLU, B. Stability of black carrot anthocyanins in various fruit juices and nectars. Food Chemistry, v. 97, n.4, p.598-605, 2006. $\checkmark$ Crossref

34. BAKER, R. A.; BERRY, N.; HUI, Y. H.; BARRET, D. M. Fruit Preserves and Jams in Processing Fruit: Science and Technology. 2. ed. New York: CRC Press, 2005.

35. ARAÚJO, J. M. A. Química de alimentos. Teoria e prática. 2a Ed., Viçosa: UFV, 1999, p. 415.

36. CORRÊA NETO, R.S.; FARIA, J.A.F. Fatores que influem na qualidade do suco de laranja. Ciência e Tecnologia de Alimentos, v.19, n.1, p.153-160, 1999. $\checkmark$ crossref

37. ALVES, R. M. V.; GARCIA, E. E. C. Embalagem para sucos de fruta. Coletânea do ITAL, v.23, n.2, p. 105-122, 1993. 
38. JAWAHEER, B.; GOBURDHUN, D.; RUGGOO, A. Effect of processing and storage of guava into jam and juice on the ascorbic acid content. Plant Foods for Human Nutrition, v.58, p.1-12, 2003. Crossref

39. DANIEL, D. E. L. Determinación de antocinaninas, fenoles totales y actividad antioxidante en licores y fruto de mora. 2009. 80f. Tese (Doutorado) Universidad Tecnológica de la Mixteca, Mixteca, ME, 2009.

40. LEITÃO, A. M. Estabilidade físico-química, microbiológica e sensorial de néctar de amora-preta (Rubus spp.), Cv. Tupy, embalado em polipropileno, no armazenamento. 2007. 64f. Dissertação (Mestrado em Ciência e Tecnologia Agroindustrial), Faculdade de Agronomia Eliseu Maciel, Universidade Federal de Pelotas (UFPel), Pelotas, RS, 2007.

41. COUTO, M. A. L.; CANNIATTI-BRAZACA, S. G. Quantificação de vitamina $C$ e capacidade antioxidante de variedades cítricas. Ciência e Tecnologia de Alimentos, v.30, Supl.1, p.15-19, 2010. Crossref
42. YU, L.; HALEY, S.; PERRET, J.; HARRIS, M.; WILSON, J.; QIA, M. Free radical scavenging properties of wheat extracts. Journal of Agricultural and Food Chemistry, v.50, n.6, p.1619-1624, 2002. PublMed

43. KUSKOSKI, E. M.; ASUERO, A. G.; MORALES, M. T.; FETT, R. Frutos tropicais silvestres e polpas de frutas congeladas: atividade antioxidante, polifenóis e antocianinas. Ciência Rural, v.36, n.4, p.1283-1287, 2006. Crossref

44. KATALINIC, V.; MILOS, M.; MODUN, D.; MUSIC, I.; BOBAN, M. Antioxidant effectiveness of selected wines in comparison with $(+)$ - catechin. Food chemistry, v.86, n.4, p.593-600, 2004. Publ/Med

45. GARCIA-ALONSO, M.; PASCUAL-TERESA, S.; SANTOS-BUELGA, C.; RIVAS-GONZALO, J. C. Evaluation of antioxidant properties of fruits. Food Chemistry, v.84, n.1, p.13-18, 2004. Crossref.. 